\title{
AS MILICIAS NACIONAIS.
}

\author{
JEANNE BERRANCE DE CASTRO \\ Faculdade de Fliosofla, Clências e Letras de Río Claro \\ (São Paulo).
}

As milícias nacionais - herança ideológica do século XVIII tiveram na milícia norte-americana e nas Guardas Nacionais francesa e também brasileira expressivos exemplos dessas fôrças paramilitares. O conceito da "nação em armas", institucionalizado, possibilitou ao poder civil o contrôle militar, auxilado de outro lado pela descentralização dessas milícias nacionais que, com isso, suplantaram as fôrças militares regulares. O militar do século XIX, alijado do mundo da política e dos negócios e substituído como profissional, pelo cidadão soldado, passou para uma posição secundária especialmente no Brasil e Estados Unidos, onde o perigo de uma guerra externa parecia remoto. Na França, logo após a queda de Napoleão. o mesmo fenômeno se repetiu. A valorização dos ideais pacifistas e a Guarda Nacional caminharam juntos.

Mas, o serviço militar, prestado pelos cidadãos a seu país como dever cívico - é um fenômeno registrado pela História em diferentes épocas da vida da Humanidade. Tal serviço, exigido da população masculina, transcedia ao aspecto puramente marcial, quando pelo recrutamento, alojamento, transporte, suprimentos, se entrosava tôda a população no esfôrço de guerra. Até o século XIX, a participação dos civis nas campanhas militares era comum e mesmo mulheres e crianças acompanhavam as tropas.

Desde os mais remotos tempos - em épocas de crise - tôda a população masculina fisicamente apta via-se obrigada a guerrear. Esses soldados de emergência, equipados e armados às suas próprias custas, uma vez cessadas as hostilidades retornavam à vida civil. A habilidade e a improvisação aliada a uma coragem natural - suficientes quando se tratava de luta pela defesa de liberdades - revelou-se indequiada na estrutura de um Estado organizado em moldes ambiciosos e engajado em campanhas militares de conquista. Nêsse momento, dentro de uma estratificação social mais elaborada. os serviços militares se vão limitando a determinadas classes sociais. 
Se as milícias se revelaram atuantes na Antigüidade, do período medieval até o início dos Tempos Modernos, elas tomaram, na Europa, um maior desenvolvimento, com a retomada dos ideais de solidariedade e liberdade. Porém, as modificações decorrentes da organização militar feudal vão afetar desfavoràvelmente o desenvolvimento das milícias em muitas regiões européias. Um fator que atuou negativamente dentro dêsse sistema foi o crescimento urbano, desviando a massa camponesa das lidas guerreiras, em vista do processo de maior especialização das funções citadinas e atraindo-as para as cidades. Aventureiros e cavaleiros ambiciosos passaram a monopolizar as atividades militares, estimulados pelo atrativo econômico dos soldos e dos saques, embora a posição dos indivíduos, nas fôrças armadas, dependesse mais do grupo social de onde provinham, do que de seu esfôrço pessoal.

A arte militar adquiriu nova dimensão sob os efeitos da grande revolução técnica das armas de fogo e um treinamento militar mais complexo substituiu as antigas táticas de combates corpo a corpo. As milícias passaram a restringir-se a atividades menos importantes na defesa local, adaptando-se à estrutura militar mais elaborada que então se formava. Já no século XVI, Maquiavel pregou, em Florença, a necessidade de adotarem-se as milícias para substituir as tropas mercenárias, ao mesmo tempo, que na França, se criou a milícia dos "arqueiros livres" e os príncipes germânicos - pela falta de numerário - vão criar em suas províncias unidades de defesa semelhantes às milícias. Da mesma forma a Branka russa inaugurada por Pedro-o-Grande resultou na expansão das milícias locais, enquanto o indelningsverk sueco e o shutterif holandês mantiveram vivos na Europa a velha tradição da milícia (1).

O absolutismo do século XVIII estimulará o gôsto pela carreira das armas e o profissionalismo militar foi gradualmente se restabelecendo na Europa. A tropa passa a atrair as classes menos estáveis e desfavorecidas econômicamente, da mesma forma que regióes subdesenvolvidas e de fronteira passam a fornecer contingentes cada vez mais numerosos de soldados. O recrutamento passou a pesar mais sôbre as populações rurais, uma vez que as populações urbanas contavam com maiores recursos de fuga ao serviço militar. Os soldos, roubos e os saques representavam em estímulo econômico, completado por um início de serviço assistencial para os velhos soldados. Quanto aos altos escalões militares, a carreira militar no século XIX passou a oferecer, além do atrativo econômico, uma possibilidade de conservação do status de nobreza e era frequientemente reconhecida

(1). - Paul Schmithenner, "Militia", Encyclopaedia of the Social Sciences, ed. E. R. A. Sellgman, IX (1948) p. 473 . 
como carreira compatível com a condição de gentleman e ao mesmo tempo satisfazia o gôsto pela aventura. O profissionalismo militar oferecia lucro, honra e aventura. Embora a perspectiva aristocrática tenha retardado a introdução da moderna tecnologia a nobreza estava disponível, equipada e preparada para servir (2). Tôda a América conta entre os seus heróis nacionais, oficiais estrangeiros que combateram nas guerras de Independência,desde La Fayette até Lord Cochrane.

Os princípios revolucionários franceses do triunfo da liberdade e democracia vão fazer ressurgir o velho sistema militar baseado na solidariedade tribal e na responsabilidade coletiva. $O$ conceito da "nação em armas" resultou da adequiação entre a pressuposição original da milícia e da obrigatoriedade do serviço militar em épocas de emergência, concomitantes com a tradição de um Exército permanente de contingentes bem treinados (3).

A presença de um Exército regular, tanto no Brasil como nos Estados Unidos, ligava-se à lembrança da Metrópole e à idéia de uma instituição aristocrática, ao passo que as milícias, apareciam como a única corporação adeqüada aos novos países. A milícia passou a encarar o princípio democrático de que a defesa da Nação era da responsabilidade de todos os cidadãos (4). Nos Estados Unidos, com a Independência, o Congresso americano pressionado pela maioria dos Estados, aprovou a permanência da milícia

"the natural defense of the free state" (5).

A milícia norte-americana, anglo-saxônica de origem (6), teve a sua resposta na Guarda Nacional brasileira que nada mais era que a militia em moldes revolucionários franceses.

\footnotetext{
(2). - Alfred Vagts, History of Militarism, (New York: Norton, 1937) p. 164 [obra citada] por Morris Janowitz, o soldado profissional - um estudo social e político (Rio de Janeiro: Ed. GRD, 1967) p. 27. "Numa medida multo extensa a história dêsse militarismo de após guerra (napoleônica) identifica-se novamente com a história da nobreza feudal em tôda a parte, até mesmo na América. Os exércitos eram o sustent́́culo da agricultura em grande escala, que sem oportunidade de fornecer-lhes cereais e alimárlas e colocar os filhos mais jovens no exército e outros empregos do govêrno, em muitos lugares se terta desfeito sob o impacto do industrialismo. Essas classes das quals sairam os oficials, foram favorecidas pelas Leis do Milho e por outras medidas, mostrando que a agricultura ainda cobrava à sociedade o auxillo marcial que the prestava".

(3). - Schmithenner, op. cit.

(4). - Samuel P. Hungtington, The soldier and the State - the troy and politics of civil military relations (Cambridge: Mass. Harvard University Press, 1957) p. 167.

(5). - Ibid.

(6). - Elbridge Colby, "Militia anglo american", Encyclopaedia of the Social Sciences, IX (1948) p. 473, informa que a mllicia inglêsa existente nos tempos do rel Alfredo persistiu nos tempos medievais, quando fol revivida para suplementar os exércitos permanentes e mercenárlos inglêses que
} 
Foram a primeira Constituição brasileira e a Constituição norte-americana, de cunho liberal, marcadamente anti-militaristas, que determinaram em ambos os países o fortalecimento do poder civil. Tal fenômeno não teve correspondência em outras nações latino-americanas onde o fortalecimento do militarismo e o aparecimento do caudilhismo é um traço característico. Nos Estados Unidos a preferência pelas milícias acarretou importantes resultados para o contrôle civil. No esquema militar norte-americano onde o profissionalismo militar ainda era bastante raro, uma fôrça formada de cidadãos, não profissionais e dedicados a outros misteres, dificilmente escaparia ao contrôle civil, o que era desejável. Depois, a República deveria ser defendida pelos leais cidadãos soldados, fortalecendo a supremacia civil pela eliminação de uma fôrça militar profissional (7). No Brasil regencial, a presença de uma tropa de 1a. linha indisciplinada e controlada com dificuldade pelo poder civil, determinou o aparecimento de uma milícia cidadã, como fôrçą mais adeqüada a um Govêrno civil .

As milícias norte-americanas, estabelecidas pela Constituição dos Estados Unidos, deram ao Congresso o poder de organizá-las e controlá-las (8).

O exercício dessa autoridade pode ser dividido em duas fases: a primeira delas entre 1792 e 1903, quando a milícia esteve sob contrôle estadual, em tempo de paz e duplo contrôle em tempo de guerra. A segunda fase inicia-se após 1903, quando a milícia passou a sofrer duplo contrôle, em tempo de paz e contrôle federal em tempo de guerra (9).

Nas lutas de Independência norte-americana, foram as milícias que impediram os britânicos de utilizar a tática da contra revolu-

lutavam no continente. O isolamento insular inglês permitiu que continuasse aquele duplo sistema, quando no continente as milicias haviam entrado em declínio. A Antiga e Honorável Companhia de Artilharia do Massachussets, Boston, fundada 8 anos depois da chegada os puritanos, representa o mais antigo exemplo de transferência da velha instituiçáo inglêsa. "Militia", Max B. Garber (ed.). A Modern military dictionary, terms ancient, modern; american and foreign, (Washington: Max $\mathrm{B}$. Garber ed., s. d.) p. 230, informa que o têrmo era originalmente aplicado às tropas auxiliares empregadas e mantidas nas colônias inglêsas da América.

(7). - Samuel P. Huntington, op. cit., p. 167.

(8). - Citado por Martha Derthick, The National Guard in Politics (Cambridge: Mass. Harvard University Press, 1965) p. 1, "The Congress shall have Power... To provide for calling forth the Militia to execute the Laws of the Union, supress Insurrections and repel Invasions; To provide for organizing, arming, and disciplining the Milltia, and for governing such Part of them as may be employed in the Service of the United States, reserving States, respectively, the Appointment of the Officers and the Authority of training the Militia according to the discipline prescribed by Congress...".

(9) : - Samuel P. Huntington, op. cit., p. 170. 
ção. Preconizando a utilização das milícias, Washington entendia-as de um modo mais amplo, mais próximo do sistema militar suiço, da "totalização" da guerra, diferente da curta prestação de serviços locais da velha milícia. O Militia Act, de 1792, criou uma fôrça superior em número aos Exércitos napoleônicos (10) e determinou, que cada homem livre, capaz, branco, cidadão de seu respectivo Estado, entre 18 a 45 anos, com algumas pequenas exceções deveria ser alistado na milícia pelo capitão da companhia, com o qual deveria residir o miliciano recrutado (11). Apoiava-se esta disposição na discriminação racial, o que mais tarde foi confirmado pela National Guard sua sucessora (12) .

No Brasil colonial, as fôrças auxiliares, ao contrário do que sucedeu nos Estados Unidos, permitiram a participação de índios, negros e mestiços em corpos especiais e cuja atuação nas lutas contra os invasores estrangeiros tão importante pąpel desempenharam. Com a Guarda Nacional a inovação foi maior pela integração de todos os cidadãos eleitores, independente da côr, na primeira grande fôrça nacional.

A Guarda Nacional no Brasil, canalizara um movimento popular em direção ao nacionalismo. A adoção do nome já era uma manifestação das novas fôrças que então sensibilizaram a Nação, naquele interregno monárquico-republicano que foi a Menoridade. Há igualmente uma concordância com os Estados Unidos do fenômeno que Arthur Schlesinger classifica de vesuvian energy e que deu origem à formação de numerosas organizações voluntárias nacionais, das quais a Guarda Nacional é das mais representativas (13).

Calcada na legislação francesa a Guarda Nacional brasileira prende-se de igual forma, à sua similar norte-americana, quanto à idéia primordial da qual se originou - "a nação em armas".

Walter Millis, analisando os dois acontecimentos mais marcantes da História contemporânea e ocidental - as revoluções america-

(10). - Walter Millis, Arms and Men - a study of American Military History (New York: A Mentor Book, 1958) p. 45.

(11) . - Ibid .

(12). - O Estado de S. Paulo, 11 de agôsto de 1967. "A Comissẽo investígadora dos conflitos raciais nos EEUU solicitou hoje ao presidente Johnson a adoção de medidas imediatas para intensificar o recrutamento de cldadãos negros para a Guarda Nacional... O inquerito realizado pela comissão revela... em 404.996 oficlais e soldados das unidades terrestres da Guarda, apenas 4.463 são negros, isto $e, 1,15$ por cento... nas unldades aéreas num total de 80.882 soldados existem apenas 475 negros, isto é, 0,6 por cento...

(13). - Arthur M. Schlesinger. The Volunteers of American proceedings of the convention of National Guard, S. Louls, October 1, 1879, pp. 2-3 [citedo por] M. Derthick, op. cit., p. 19. 
na e francesa - observa que, em 1789, quando o povo de Paris derrubara a Bastilha - nova doutrina e os novos métodos demonstrados pela Revolução Americana haviam chegado, em ondas sucessivas, à França revolucionária.

Already the winds of new spirit of popular fanatic nationalism was overturning the ancient political systems; already the new energies of popular, democratic warfare were not only sweeping away the old professional royal armies; they were also giving the first grim hints of that totalitarian military distatorship in which - from the days of Napoleon to those of Hitler, Stalim, or Mao Tse-tung "peopleùs democracy" seems fated to end (14).

\title{
Em dezembro de 1789, o Relatório da Assembléia estabelera
}

\author{
"as an axion, that in France every citizen must be a soldier and \\ every soldier a citizen, or we shall never have a constitution" (15).
}

Era o mesmo espírito que levara os estadistas americanos a sujeição do Exército regular e a conseqüente valorização da milícia.

Organizadas expontâneamente após a crise de 14 de julho de 1789, foram regularizadas por numerosas Leis da Assembléia Constituinte, das quais a primeira foi a de 1791 (16). A Garde nationale motivada por razões políticas ou melhor nacionais, lançou o ideal do cidadão nacional, do "patriota". Conferiu à milícia burguesa, municipal, um aspecto nacional, transformando-a. E' La Fayette quem diz:

Voici 4 millions d'hommes en armes pour faire respecter leurs droits et les vôtres... Je vous apporte une cocarde que fera le tour du monde, et une institution tout à la fois civile et militaire, qui changera le système de la tactique européene et réduira les gouvernements absoluts à iniciative d'être battus s'ils ne l'imitent pas et d'etre renversés s'ils osent l'imiter (17).

A Assembléia francesa, ao chamar o Exército para a defesa externa e destinar uma milícia treinada para a defesa interna. de

\footnotetext{
"armed citizens ready to defend their homens and freedom",
}

segundo Walter Millis, tem uma imensa'semelhança com o sistema militar que os políticos federalistas americanos estavam tentando criar nos Estados Unidos naquele momento. Assim como, na França revolucionária, uma milícia bem treinada era o palladium of the Constitu-

(14). - Walter Millis, op. cit., p. 47.

(15). - Ibid., p. 48.

(16). - Louis Girard, La Garde Nationale 1814-1871 (Paris: Plon, 1964) p. 7.

(17). - Ibid., p. 364, 365. 
tion, para Washington era o palladium of our security. Nos Estados Unidos, cada homem capaz era obrigado a armar-se, 'ao passo que, na França, êle era recognized as an active citizen only to the extent that he has procured weapons. A levée en masse tivera a sua correspondência na medida tomada por Washington, 10 anos antes, para a formação de um Exército permanente. Para Millis, tais fatos demonstram que, em qualquer tempo de crise nacional, estas idéias são levadas a têrmo (18). Quanto ao Brasil, segundo observação de Justiniano José da Rocha

"não havia exército e a fôrça armada que existia era a cidade inteira, obedecendo temporàriamente a chefes de sua escolha" (19).

Assim como na Inglaterra e Estados Unidos, o espírito das milícias tem sido repetidamente invocado contra as manifestações ameaçadoras da ditadura militar ou autoritarismo centralizados (20), no Brasil, a milícia cívica teve, como base, também a reação contra o militarismo e o autoritarismo de Pedro I.

\footnotetext{
"Contra o motim e a insurreição empregou a democracia dois remédios heróicos, o licenciamento do Exército e a criação da guarda cívica" (21).
}

As Independências norte-americana e brasileira, dirigidas contra tropas profissionais, certamente não estimulariam as simpatias pelo profissionalismo miltar. As clases revolucionárias, em ambos países, não tiveram o cunho militar e o prestígio e o poder permaneceram com os civis. A idéia de que o poder civil devia sobrepujar o militar era da tradição democrática dos círculos liberais da Inglaterra e da França. A Revolução Francesa introduziu a concepção da superioridade das milícias cidadãs, certamente imunes ao militarismo e ao despotismo. Da mesma forma, foi tradicional a hostilidade e a má vontade das fôrças regulares militares para com os cidadãos soldados. Exemplificando essa mentalidade anti-militarista da época, temos:

Os norte-americanos não tem vizinhos, por conseguinte grandes guerras, crises financeiras, destruição e conquista a temer. Não tem necessidade de grandes impostos, nem de Exército numeroso, nem grandes generais. Não tem quase nada que temer de um flagelo mais terrível para as repúblicas que todos. êsses juntos, que é a glória militar (22).

(18). - Walter Millis, op. cit., p. 48.

(19). - J. J. da Rocha, "Reação; Transaçāo"; Duas palavras acêrca da atualidade do Brasil", J. Magalhăes Junior, Três Panfletários do $2^{9}$ reinado (São Paulo: Companhia Editôra Nacional, 1956), p. 187.

(20). - Elbridge Colby, op. cit., p. 473.

(21). - J. J. da Rocha, op. cit., p. 180.

(22). - Alexis de Tocqueville, La democracia americana (México: Fondo de Cultura Economica, 1957) p. 298. 
A National Guard está identificada com dois antigos símbolos constitucionais: o cidadão soldado e os direitos civis. Os guardas nacionais como soldados amadores eram primeiramente cidadãos e depois soldados (23), traço também marcante na Guarda Nacional brasileira. Em 1840 nos Estados Unidos o sistema de milícia estava virtualmente morto, substituido por um corpo de voluntários bem organizado, brilhantemente uniformizado, com bom equipamento e recrutado entre uma elite social que havia sobrevivido ou estava crescendo com êles. Organizações como a artilharia da Louisiania, os azuis da Infantaria Ligeira das Rochosas ou o $7^{\circ}$ Regimento de Nova York apareceram nessa época. Adotou essa última a designação de National Guard numa homenagem a La Fayette, em sua segunda visita à América em 1824. Alguns anos depois, em 1862, o Legislativo de Nova York adotou êsse nome oficialmente (24). Entre os anos de 1881 e 1893, cada Estado da União reviu o código militar, estabelecendo e organizando as milícias e tornando oficial o nome da Guarda Nacional (25). Històricamente, a National Guard era uma fonte de favores políticos dos governadores e até mesmo dos membros do Congresso. Muitos oficiais estavam engajados em atividades partidárias, ao mesmo tempo que desempenhavam funções na milícia. As atividades políticas dos oficiais aumentaram suas ligações com os membros do Congresso (26) . Em 1879, reuniram-se, em Nova York, dezenove representantes dos Estados e formaram a National Guard Association cujas duas principais metas eram: assegurar a assistência federal e tornar-se reserva do Exército e manter seu status legal, como fôrça militar estadual em tempo de paz, o que a deixaria livre do contrôle federal. Essa Associação era formada apenas de oficiais e pertencer a ela tornou-se tradição em muitas famílias.

Martha Derthick é quem afirma que muitos dêsses homens se sentiam atraídos pelo serviço na National Guard, porque haviam falhado na vida privada, procurando, então, outras satisfações. Lá estavam cercados pela autoridade do grau e prestígio do uniforme de oficiais do Exército dos Estados Unidos. Além do mais, aquêles que sentiam vocação para a carreira das armas, subiam de pôsto muito mais ràpidamente do que no Exército, pois, ambas as corporações estavam organizadas de modo semelhante. O que certamente também pesaria era o fato de não ser necessário, com o ingresso na National Guard, cortar os laços que os prendiam à comunidade para sofrer as rudezas da vida dos soldados profissionais. A National

(23). - Samuel P. Huntington, op. cit., p. 167.

(24). - Walter Millis, op. cit., p. 89.

(25). - Martha Derthick, op. cit., p. 16.

(26). - Ibid., pp. 3, 4, 5 . 
Guard possibilitava-lhes participar, ao mesmo tempo, do mundo civil e do mundo militar (27).

Muitas destas características aparecem na Guarda Nacional brasileira depois da reforma de 1850 , mas, sobretudo com uma acentuação das características políticas em detrimento das militares. A Guarda Nacional, na sua primeira fase democrática (1831-1850) de intensa atuação militar e policial, à medida que a pacificação foi se impondo e o Exército reorganizando-se, perdeu sua principal razão de ser. Se a Guarda Nacional brasileira se originou do modêlo francês, são numerosos os pontos de contacto entre ela e a National Guard norte-americana. Em 1832, nos Estados Unidos, considerava-se as milícias como a melhor corporação para a defesa interna e o Exército mais adeqüado para o ataque e defesa. Predominava a conviç̧ão de que, em todos os tempos, grandes Exércitos se tornaram perigosos para as liberdades civis, ao contrário da milícia, porque formada ùnicamente de cidadãos armados para a preservação de sua própria liberdade (28). A mesma argumentação é encontrada nas discussões do Parlamento brasileiro, quando da adoção da Lei de criação da Guarda Nacional e também nas discussões para o estabelecimento dos efetivos militares nos sucessivos anos financeiros. O Exército norte-americano permaneceu com um efetivo pequeno e estático de cêrca de 6.000 homens, durante largos anos (29). Da mesma forma, o Exército brasileiro imediatamente após a Lei de 1831 teve reduzido consideràvelmente o seu efetivo, permanecendo baixo até os primeiros atritos no Prata, quando tal prática foi sendo interrompida. No seculo XIX, o comportamento organizacional da profisâo militar norte-americana mostrou importantes diferenças com relação a seus equivalentes europeus devido a diferenças na estrutura na sociedade civil e dos valores nacionais. Quando do aparecimento da milícia norte-americana e da Guarda Nacional brasileira a guerra era uma realidade distante.

A observação de Morris Janowitz de que o Exército norte-americano permaneceu pequeno, quase minúsculo, de modo que a principal fonte de potencial humano se concentrou na milícia estatal, aplica-se também ao Brasil. Da mesma forma que a larga utilização de voluntários nos Estados Unidos, em tempo de paz, o sistema de qualificação para a Guarda Nacional no Brasil significava que eram ainda as camadas mais baixas da sociedade que supriam o material huma-

(27). - Martha Derthick, op. cit., p. 3-5.

(28). - William H. Summer, "An Inquiry into the Importance of the Militia in a Free Commonwealth" (Boston, 1823) p. 7 and passim, [obra citada]

(29). - Ibia. por Walter Millis, op, cit., p. 76. 
no. Esse sistema militar desmoronou com a eclosão do primeiro grande conflito (30). Durante a guerra de 1812, o Govêrno, apoiado na Constituição, convocou as milícias de Massachussets e Connecticut e ambas recusaram enviar contingentes. Alexis de Tocqueville considerava que a maior felicidade, dos Estados Unidos não era ter encontrado uma Constituição federal que lhe permitisse sustentar guerras mais sim, estar situado de tal maneira que não havia perigo de enfrentá-las (31). Para Emory Upton, os anos de 80 e a guerra mexicana marcaram o fim do sistema de milícias e a

"revolution in our military policy" (32).

Quanto ao Brasil, depois da guerra do Paraguai, a Guarda Nacional pràticamente desapareceu, orientando-se pelo sistema europeu. dando maior ênfase ao Exército permanente, com reservas treinadas e profissionalização de sua oficialidade (33).

Nos Estados Unidos, sòmente depois da guerra hispano-americana que o Milictia Act de 1792 foi derrubado, substituido, no seu antigo conceito, pela National Guard, que deveria permanecer através de vicissitudes e modificações, como a maior esperança da Nação e reserva de combate. No Brasil, a Guarda Nacional, apesar de sua intensa atuação militar nas campanhas de pacificação, sobretudo no Sul (raramente mencionadas), nunca foi realmente considerada uma reserva militar, porque quando militarizada, se integrava na estrutura militar do Exército regular.

Quanto a possibilidade da Guarda Nacional transformar-se em instrumento militar, a desorganização e a pobreza de recursos matetiais com que lutou, aliada ao inexistente estímulo econômico da carreira militar, dentro de uma liderança política essencialmente anti-militarista, impediu qualquer veleidade nesse sentido. Da mesma forma, Walter Millis considera que a rica, amorfa e variada vida nacional norte-americana não oferecia oportunidade real para a National Guard transformar-se em importante instrumento da classe militar.

A utilização de uma fôrça paramilitar, como foi a Guarda Nacional, como instrumento social nas sedições locais, é outro ponto de analogia entre as três instituições - francesa, brasileira e norte-americana. Estando para ser feito o estudo das revoluções da Menoridade

\footnotetext{
(30). - Morris Janowitz, o soldado profissional - um estudo social e politico, (Rio de Janeiro: ED. GRD, 1967) p. 28.

(31). - Alexis de Tocqueville, op. cit., pp. 159-160.

(32). - Emory Upton, The Armies of Asia and Europe (New York: Appleton, 1878) [citado por] Walter Millis, op. cit., p. 93.

(33). - Morris Janowits, op. cit., p. 28.
} 
brasileira - especialmente no campo mais amplo das implicações sociais e raciais - esta deficiência impede uma melhor compreensão da ação da milícia cidadã e sobretudo do seu possível compromisso com aquêles movimentos. Uma das raras rebelióes estudadas, no que representou de agitação social, foi a Revolução Praieira. Uma das questões postas em foco pela rebelião - a nacionalização do comércio a retalho - já havia sido levantada anteriormente pelos jornais da Guarda Nacional em 1836 e 1849 e o próprio movimento praieiro, defendido pelo jornal $O$ Guarda Nacional, alerta, alerta. Sòmente o estudo da documentação sôbre a Guarda Nacional pernambucana permitiria conclusões mais sérias a êsse respeito.

Na própria Assembléia, em 1850, apontou-se a Guarda Nacional como elemento perturbador da tranquiilidade pública e participante nos movimentos revolucionários. tanto na Bahia de 1837 , como em Minas Gerais e São Paulo, em 1842. Se bem que, anteriormente, durante a Cabanagem, guardas nacionais não quizeram marchar voluntàriamente para Jacuhipe, como informava a Aurora Fluminense, tornou-se necessário requisitar a Guarda Nacional, uma vez que a tropa regular não era suficiente (34). Da mesma forma, a dissolução de numerosos corpos da Guarda Nacional mineira, em 1842, e a dissolução da Guarda Nacional paraense, por longos anos, nos levam a pensar nos possíveis compromissos sociais da Guarda Nacional com movimentos populares.

Na França, a Guarde nationale representou a ação de uma burguesia armada contra o proletariado. O homem do Ancien Regime e pós-revolucionário viveu numa insegurança que durou até 1850 . Era comum, na Paris do século XIX, a identificação da massa operária com os marginais, criminosos, considerada temível como grupo, sendo corrente a confusão entre as classes laboriosas e as classes perigosas (35). Essa situação modificou-se na segunda metade do século XIX, em decorrência do progresso econômico. Dessa forma, a questão social era encarada apenas como um problema de segurança e a Guarda Nacional, o instrumento da manutenção do status quo. Quando Napoleão desejou engajar operários como oficiais da Garde nationale, houve forte oposição à formação de uma Guarda popular (36). Todavia, uma Guarda Nacional composta de proletários e adolescentes existiu em Avignon, em 1819, e parece mesmo que em outras cidades (37), mas o mêdo de armar operários ainda era grande em 1830. Frequientemente o armamento para a milícia cívica era pedido no

(34). - Aurora Fluminense (Rio de Janeiro), n. 892, de 28 de março de 1834.

(35). - Louis Girard, op. cit., p. 363.

(36). -.Ibid, , p. 12.

(37). - Ibid., p. 103. 
sentido de proteger os proprietários contra os operários (38). La Fayette, em 1830, sugeriu ao soberano:

'il faut que vous expliquez au roi que le seul moyen d'avoir la paix et le repos en France, c'est de comprende dans la garde nationale tous les ouvriers sans exception. Il faut les avoir tous, et comme ils auront intérêt à la tranquilité, on pourra être assuré que toute révolution sera désormais impossible",

ao contrário do pensamento oficial de que,

"armer les ouvricrs c'est amener l'émeute et enfin rénouver 1793 et ses mille horreurs" (39).

\section{A Garde nationale transformou-se em uma}

"milice bourgeoise armée pour la défense des intérêts privés"... mas, sòmente mais tarde, "ce droit au fusil si violemment dénié aux pauvres, on allait l'imposer aux riches, mais pour la défense nationale et non plus celle des propriétés" (40).

A burguesia na milícia francesa lutou sobretudo pela preservação de seus privilégios e pela "revolução moderada", protetora da ordem e da propriedade (41).

Nos Estados Unidos, na segunda metade do século XIX, entre recrutar-se um grande Exército e reorganizar-se a milícia como Guarda Nacional - para dominar a turbulência existente - optou-se pela segunda alternativa. Assim, nos anos 80 , passou a reprimir "facções populares", a sufocar greves, atuando como reserva militar (42). Marta Derthick observa que há uma relação entre as greves trabalhistas de 1877 e o crescimento da National Guard. Inquestionàvelmente, a prepotência industrial aumentava bastante o ímpeto daquêles movimentos e os governos estaduais e locais utilizaram abertamente as fôrças milicianas contra os "anarquistas, internacionalistas e nihilistas". O desenvolvimento da National Guard principiou a fazer-se mais intenso nos populosos Estados industriais do Norte e Centro Oeste, como Massachussets, Connecticut, New York, Pensylvania, Ohio e Illinois. Além do auxílio oficial, recebeu a National Guard substanciais doações de poderosos capitalistas. Na maioria dos Esta-

(38). - Ibid, , p. 174 .

(39). - Ibid., p. 180-181. Girard refere-se à exibiçăo de uma peça teatral em 1830, La coalition des ouvriers em que a platéia aplaudiu com entusiasmo uma cena em que guardas nacionais aparecem reprimindo uma greve. Dois anos mais tarde, por ocasião da greve dos chiffoniers, pela primeira vez a Garde nationale entrou em açáo a favor de uma greve.

(40). - Ibid., p. 345-346.

(41). - Louis Mandelin, La Révolution (119 ed.; Paris: Hachette, 1926) p. 79.

(42). - Walter Millis, op. cit., p. 128-129. 
dos, eram os oficiais da National Guard homens de negócio e profissionais representativos das "melhores classes". Não considera a autora, como único motivo do crescimento da National Guard, o interêsse dos grupos e dos governos estaduais na conservação da ordem doméstica, mas lhes reconhece a importância (43).

Quanto à Guarda Nacional brasileira da sua primeira fase (18311850) democrática, popular na sua composição (44), diferenciou-se da Garde Nationale, da qual se originou e da National Guard, da qual se aproximou tanto posteriormente.

No Brasil rural e escravocrata e na sociedade pouco diversificada daquele momento, com ausência de uma burguesia, teve ela que adaptar-se a existente classe livre, modesta e trabalhadora, fortemente "colorida". Mas não fôra a Guarda Nacional criada com intuitos revolucionários e sim conservadores, o que foi confirmado por Evaristo da Veiga, menos de um ano após sua criação, quando declarou pelas páginas da Aurora Fluminense, que era

"deshonroso a qualquer um ter-se-lhe confiado a defesa de seus bens e a do Estado, entregando-lhes essas espingardas que eram antes trazidas por gente que tantas vêzes ameaçou o nosso repouso e propriedades" (45).

Na França, os guarda-nacionais, apelidados de baionettes inteligentes, defenderam melhor as propriedades que o Estado (46). No Brasil, poderiam ter-se transformado em instrumento de mudança social por intermédio do sistema eletivo de acesso ao oficialato por quatro anos. Mas, tôdas as possibilidades de afirmação social e racial foram interrompidas e desviadas pelas modificações decorrentes da descentralização - reflexo do Ato Adicional -, ligando estreitamente a milícia cidadã aos interêsses da política local. A reação das classes conservadoras, que controlavam a liderança nacional, retirando-lhes o poder democrático do voto e a temporariedade dos postos, sujeitou-as ao arbítrio provincial totalmente dependente do poder central. A reforma de 1850 nada mais fêz do que oficializar aquelas alterações no sentido de um maior contrôle político central, mas, sobretudo, tornou a Guarda Nacional brasileira um instrumento social da classe conservadora na manutenção de seus privilégios, anulando legalmente tôdas as suas características democráticas e aproximando-a de suas congêneres estrangeiras .

(43). - Martha Derthick, op. cit., p. 16-17.

(44). - O Povo em Armas, Guarda Nacional 1831-1850 (Tese de Doutoramento, Universidade de São Paulo, 1968).

(45). - Aurora Fluminense (Rlo de Janeiro), n. 617, de 16 de abril de 1832.

(46) . - Louis Girard, op. cit., p. 64, 327. 